\title{
REFLEXÕES SOBRE A INTERVENÇÃO NO RIO DE JANEIRO
}

\section{ARTIGO ORIGINAL}

VITORINO, Marcelo da Silva ${ }^{1}$

VITORINO, Marcelo da Silva. Reflexões sobre a Intervenção no Rio de Janeiro. Revista Científica Multidisciplinar Núcleo do Conhecimento. Ano 04, Ed. 10, Vol. 06, pp. 79-101. Outubro de 2019. ISSN: 2448-0959, Link de acesso: https://www.nucleodoconhecimento.com.br/comunicacao/intervencao

\section{RESUMO}

Este trabalho tem como objetivo estudar o comportamento da opinião pública em torno da Intervenção Federal na segurança pública do Rio de Janeiro, com foco nas opiniões políticas do espectro de direita. Foram usadas como referencial teórico as reflexões de Raoul Girardet em seu livro "Mitos e Mitologias Políticas". O corpus para o estudo de caso se compõe de publicações e comentários em páginas do Facebook entre os dias 16 e 27 de fevereiro de 2018. Em um ambiente no qual os meios de comunicação de massa trabalham pelo controle ideológico do público, as manifestações sobre a intervenção federal no Rio de Janeiro respondem antes às preocupações com a ideologia do que aos acontecimentos.

Palavras-Chave: Intervenção Federal, conspiração, mídia, organização, Exército Brasileiro.

\section{INTRODUÇÃO}

A Intervenção Federal na Segurança Pública do Rio de Janeiro ocupou o primeiro plano do debate público nacional entre os dias 16 e 27 de fevereiro de 2018. A atenção

1 Graduado em Ciências Militares (Academia Militar das Agulhas Negras, 2005), Mestrando em Comunicação Social (Centro de Estudos de Pessoal e Forte Duque de Caxias, 2019). 
dedicada ao evento não foi consequência de seu ineditismo, natureza, ou mesmo pelas ações do Interventor, do Comandante do Exército ou do Presidente da República. Através da Intervenção, foi possível a parte da opinião pública recortar fatos, eventos e declarações de autoridades públicas que, de alguma maneira, confirmavam sua visão de mundo. Nesse contexto, o espectro conservador pôde apontar a corrente adversária como subversiva defensora de "bandidos" e da destruição dos valores morais da sociedade, a principal causadora da violência a qual o Exército, por meio da Intervenção Federal, viria finalmente para eliminar.

O objetivo geral desse trabalho é estudar esse ambiente de efervescência mitológica em torno da Intervenção Federal na segurança pública do Rio de Janeiro, com foco nas opiniões políticas do espectro de direita. A pesquisa se concentrará nos primeiros doze dias da Intervenção Federal no Rio de Janeiro, entre seu anúncio em 16 de fevereiro e a primeira coletiva de imprensa da equipe do interventor, com o chefe de gabinete e o secretário de segurança pública, em 27 de fevereiro; é o período quando, mais provavelmente, os estereótipos, crenças e valores previamente arraigados no público ainda não foram alterados em vista de outros acontecimentos. Destaca-se que, conforme Duarte (2017, p. 221), "os estudos de caso são generalizáveis a proposições teóricas e não a populações ou universos.

Os dados serão retirados de comentários nas mídias sociais, e a análise seguirá como paradigma de comparação o trabalho de Girardet (1987), que identificou no imaginário político da França Republicana quatro "mitos" que se repetiam periodicamente. Dentre estes, o mito da "Conspiração" será utilizado para elucidar os aspectos principais do discurso conservador em torno da Intervenção Federal.

\section{O BRASIL E AS IDEIAS CONSERVADORAS}

Ernesto Araújo (2017) diz que a ideia de nação está ligada ao nascimento do Ocidente. As cidades gregas do século $V$ a.C. reagiram à ameaça de invasão persa formando uma aliança singular: uma comunidade de nações independentes entre si, mas que ao mesmo tempo se imaginavam como um conjunto diferente não apenas dos persas, mas de todo o resto do mundo, unidas para defender sua herança cultural, sua família, 
sua liberdade e, principalmente, seus deuses. Os gregos poderiam ter se rendido diante de forças muito superiores e se tornado parte de um império multicultural (o que acabará acontecendo quando da dominação pelo Império Romano). Do ponto de vista puramente racional, faria todo o sentido para a preservação da vida. Mas a pátria era uma emoção, um conjunto de sentimentos que tomava forma política, ainda que não fosse essencialmente político.

O patriotismo pertence, portanto, à essência do Ocidente. Não foi pensado pelos filósofos, foi sentido pelos homens diante do perigo da morte - e não esqueçamos que, para os que conhecem a "metafísica da guerra" conforme a expressão de Julius Evola, o grito que nasce no peito de um homem na hora da batalha é sagrado, não provém dele, mas the é inspirado pelo deus. (ARAÚJO, 2017, p. 337)

Sob o manto da "sensação de pertencimento a alguma ordem social contínua e preexistente" (SCRUTON, 2015b, p. 54), o conservadorismo moderno é o herdeiro direto da tradição de consagração de um povo aos mistérios divinos. $E$ todo povo tem o seu mito fundador. Carvalho (2000) mostra como a mística da expressão Gesta Dei per Francos (a obra de Deus por mãos francesas), referência ao cristianismo militante das Cruzadas, sobreviveu até o século XX, e nela acreditavam Maurice Barrès, Jacques Maritain, Charles Péguy e Georges Bernanos, e até o ateu François Mitterrand parecia ser devoto dela. O Brasil não será diferente:

O historiador Vítor Manuel Adrião vê nas navegações portuguesas um grande ritual iniciático, e, portanto, o Brasil, fruto supremo desse "mistério", tem uma origem profunda e sagrada, ligada aos mais profundos arcanos da alma ocidental tal qual manifestados na nação portuguesa. (ARAÚJO, 2017, p. 343)

Uma posição política conservadora, ou "de direita", será aquela que tenta derivar sua autoridade da tradição. Kirk (2013, p. 104) dirá que "a continuidade histórica da experiência de um povo, diz o conservador, oferece um guia político muito melhor do que os projetos abstratos dos filósofos dos cafés." O americano explica que o conservadorismo não é uma ideologia fixa, e que os conservadores colocarão em relevo princípios mais ou menos diferentes, dependendo das circunstâncias e necessidades daquele período. Na segunda metade do século $X X$, ele diz que o conservador acredita que há uma ordem moral duradoura e que há uma forma de 
consagração pelo uso; defende comunidades voluntárias e se opõe a um coletivismo involuntário; vê a necessidade de limites prudentes sobre o poder e as paixões humanas, prestam atenção ao princípio da variedade e são guiados pela prudência. Em uma linguagem diferente, trata-se da mesma realidade que em Ernesto Araújo transformou-se na celebração dos mistérios nacionais: uma espécie de nobreza da alma que deve ser perseguida, e que uma vez encontrada, servirá de guia na condução das coisas humanas. É o que Burke (2014, p. 98), citado frequentemente como o pai do conservadorismo moderno, afirmou em sua crítica à Revolução Francesa.

Nesse nosso mundo europeu, nada é mais certo de que nossa civilização, nossos costumes, e todas as boas coisas que dele decorrem, dependeram durante séculos de dois princípios; e resultaram, sem dúvida, da combinação de ambos: aludo ao espírito do cavalheirismo e ao espírito da religião.

O Brasil se estrutura em torno da colonização europeia. O mito da fusão de raças, criado às pressas nos anos 1930 como resposta ao chauvinismo racista de nações europeias, não representaria verdadeiramente as origens da nação brasileira, onde o negro e o índio foram de fato assimilados não apenas à língua, mas à organização social e política europeia. Esta organização, entretanto, já é aquela da Baixa Idade Média, na qual a transcendência desviada tornou-se a norma. Voegelin (1999), discutindo o problema da colaboração das Igrejas alemãs com o governo nacional socialista ascendente, lembra novamente de como Tomás de Aquino caracterizava o todo da humanidade, inclusive os pecadores, como membros do corpus mysticum de Cristo, mostra como rapidamente a Igreja Católica reduzirá o corpus mysticum de Cristo de toda a humanidade para apenas os membros da própria Igreja. As Igrejas protestantes já nascem com essa visão. Em Calvino, por exemplo, os pecadores não participam da graça de Deus. Como mostra Weber (2004), a ética calvinista - ou ao menos seus pontos principais - penetra na corrente cultural de todo o Ocidente como o "espírito" por trás do desenvolvimento econômico moderno. O "deus" que grita no peito de navegadores, bandeirantes, e senhores de engenho é o do sectarismo e da acumulação de riquezas, que reina na cidade mítica de Eldorado. Por isso Rodríguez (2017), por exemplo, diz que a fazenda e o engenho foram a escola prática da vida 
política brasileira durante três séculos, treinando o brasileiro para a submissão incondicional ao senhor e à defesa dos interesses familiares do clã. Dessa maneira, ao contrário do espírito de comunidade apontado por Ernesto Araújo na aliança dos gregos contra os persas, os brasileiros se caracterizariam pela falta de solidariedade nas relações sociais.

Em que pese o fato de a nossa sociedade ter-se transformado radicalmente ao longo do século $\mathrm{XX}$, sobretudo a partir do processo de industrialização e de urbanização, fortemente acelerados nos últimos 40 anos, não podemos negar que uma das características marcantes da nossa vida social é o insolidarismo. O país cresceu populacional e politicamente. As velhas estruturas rurais deram lugar à sociedade industrial e urbana. No entanto, não foram modificados os valores. O secular espírito de "patota" e insolidarismo, que é seu corolário, estão presentes em todas as partes. No Brasil o "patotismo" sufocou o patriotismo. (RODRÍGUEZ, 2017, p. 76)

Evidentemente há uma espécie de cor local no "patotismo" identificado por Vélez Rodrigues, mas o hiato entre a ordem conservadora ideal e aquela realmente existente não é uma exclusividade brasileira. Mills (1981, p. 381) levanta praticamente os mesmos problemas em outro país nascido dos "mistérios" ocidentais celebrados no continente, os Estados Unidos. Respondendo diretamente à leitura de Kirk, o autor escreve que

A tradição é sagrada; através dela, as tendências sociais reais da Providência se revelam; portanto, a tradição deve ser nosso guia. O que é tradicional representa a sabedoria acumulada das idades, e mais ainda: existe pela "vontade divina". Naturalmente devemos indagar como saberemos quais as tradições utilizadas pela Providência. Quais os acontecimentos e transformações à nossa volta devidos à vontade divina? E em que momento as tramoias altamente conscientes dos Fundadores da Pátria se tornaram tradicionais e, portanto, santificadas?

Mills (idem, p. 382) prossegue questionando a crença conservadora de que, se não destruirmos a ordem de classes e a hierarquia dos poderes, então teremos líderes e superiores para nos traduzir essas intenções da Providência, o que a simples tentativa de construção coletiva do mundo não só não consegue fazer, como provavelmente ainda destruirá o que deveria ser construído. Diz que, no fim, o conservador clássico fica com "o princípio de aceitar agradecidamente a liderança de alguns homens que 
considera como a elite santificada." Ele opõe a imagem idealizada do conservadorismo à realidade de que a única experiência na qual os muito ricos nos Estados Unidos podem servir de exemplo é a de ganhar dinheiro, pois culturalmente estão entre os mais pobres do país. Eles não podem fazer como os conservadores europeus, que de alguma forma puderam contrastar a antiga nobreza feudal à vulgaridade do capitalismo burguês, pois na América a burguesia domina desde o início. Ali não há nem pode haver um conservadorismo de tipo clássico.

A direita brasileira, porém, resolverá esse problema de modo bastante peculiar. Falando sobre o que denominou como "festas da ordem", Da Matta (1986, p. 87) aponta que "o universo da sociedade é lido ou apresentado a partir do código de Estado na sua vertente mais forte, mais ordenada e, talvez por isso mesmo, mais patriótica: a de suas Forças Armadas." O antropólogo compara as comemorações do dia da pátria nos Estados Unidos, onde famílias realizam piqueniques nos parques e jardins das cidades, com as do Brasil, onde há uma parada militar ${ }^{[2]}$. O patriotismo brasileiro se materializa na imagem do soldado. Besançon (1997, p. 27) diz que na pólis grega, cabia ao artista, fosse ele o escultor, o músico ou o ator, representar para os cidadãos a presença do deus entre eles: "por isso, Hegel via no artista o verdadeiro teólogo da religião grega". Pois os militares são, então, os sacerdotes e teólogos da nação brasileira. O papel ordenador das Forças Armadas é idêntico ao do deus grego, e apenas a elas é atribuído o poder de retirar o país do provincianismo das patotas e recolocá-lo em seu lugar verdadeiro junto aos países mais sérios. Aos militares, como sacerdotes-artistas, cabe representar diante do povo o mistério fundador da nação, a vinculação da alma ao seu próprio destino por meio do sacrifício ao bem comum.

Garshagen (2015, p. 260) discute a forma excêntrica com a qual os brasileiros têm uma imagem negativa dos políticos, mas acreditam que o governo deve resolver todos os seus problemas. "Estranhamente, não o identificamos com o governo que efetivamente existe, mas com uma espécie de instituição virtuosa que só existe em sonhos dourados." Mas o "estatismo" é mais consequência do que causa. Se o brasileiro tem mesmo maior lealdade à patota do que à pátria, ainda assim não deixa de reconhecer a importância desta última: apenas não se sente merecedor de falar 
por ela, e espera que outros, para isso escolhidos, o façam. Os políticos são odiados porque, diferente dos militares, são escolhidos para representar o mistério da pátria mas faltam a seu dever, quase sempre flagrados colocando interesses grupais acima do interesse nacional.

Nesse ponto, porém, é que surge a tensão que caracteriza a relação entre as Forças Armadas e o conservadorismo nacional. Este último costuma atribuir àquelas papéis muito diferentes daquele que elas estão, tradicionalmente, dispostas a realizar. Gordon (2018, p. 241), bem como Olavo de Carvalho ${ }^{[3]}$, argumentam, por exemplo, que o grande erro dos militares do regime de 1964-1985 foi se concentrar apenas no combate às guerrilhas marxistas na cidade e no campo, onde foram bem sucedidos, mas ter, ao mesmo tempo, negligenciado o que ambos chamam de "guerra cultural", ou o controle do imaginário nacional através da mídia.

Alheios à ênfase lukácsiana na totalidade do real, e portanto restritos à observação de partes isoladas da esquerda política, [o general] Golbery e os militares não apenas foram incapazes de nota-lo, como, carentes de intelectuais orgânicos na imprensa, nas artes e no âmbito da cultura em geral, e objetivando algum grau de legitimação do regime, acabaram tendo que ceder à intelectualidade esquerdista naqueles domínios.

A observação pareceria estranha, uma vez que é o próprio Carvalho (2014, p. 171) quem explica que "as armas usadas na guerra cultural são, por definição, uma propriedade quase monopolística da classe dos intelectuais e estudiosos." Os estudos necessários para a compreensão e percepção completa dessas operações de guerra cultural são complexos, envolvendo história literária e cultural, filosofia, linguística, semiologia, arte retórica, psicologia e até sociologia da arte; enquanto as elites governantes, inclusive militares, em países de terceiro mundo concentram-se em estudos de administração, economia, direito, diplomacia e ciência política. Entre os conservadores brasileiros será um tabu especular que, se aquela guerra cultural foi perdida para a tão temida esquerda, foi porque essa teve ao menos o interesse de nela lutar. O revolucionário está disposto a, ele mesmo, transformar a realidade e mudar o mundo, mesmo quando não sabe exatamente o qual é o mundo que está sendo transformado ou em quê. Uma verdadeira ênfase na totalidade do real lukácsiana mostraria que militares, por definição, realizam apenas uma das muitas 
tarefas políticas em uma sociedade industrial complexa, não necessariamente a de polícia política de direita. E mesmo na hipótese de que o fossem, já estavam ocupados em um combate letal contra guerrilheiros. Teria sido de bom tom que os conservadores do período se mobilizassem para realizar aquilo que acreditavam ser o necessário para o momento. E se não o fizeram, foi pela dificuldade, mesmo diante das circunstâncias adversas, de abrir mão do mito de um guiamento benévolo por uma elite superior e pela Providência.

\section{A ORGANIZAÇÃO INIMIGA}

Figura 1 Comentário de internauta, Página Joice Hasselmann, 26 de fevereiro de 2018

Wilson Fernando Borges Estamos vivendo uma tomada de poder igual a 1964 só que totalmente light e homeopática, mas já é alguma coisa...agora a coisa vai....ponham as barbas de molho comunistada...

Curtir · Responder $\cdot 48$ sem

Diante da Intervenção Federal no Rio, dois sentimentos conflitantes se desenvolvem nessa parte do público: satisfação e desconfiança. De um lado, há a real possibilidade de que as quadrilhas de criminosos sejam desmanteladas e os índices de violência reduzidos. Por outro, há alguma descrença na possibilidade de que esses resultados sejam permanentes ou mesmo suficientes, em consequência da decadência moral que o país atravessaria. A direita parte da ideia de que o Brasil já vive sob a "inextinguível vontade de poder" (1987, p. 36) da "Organização" (idem, p. 32), e que é necessário libertar-se desse domínio. 
Figura 2 Comentário de internauta, The Intercept Brasil, 27 de fevereiro de 2018

Sergio Vargas O Brasil já está entregue a uma ordem pior ... as dos bandidos armados até os dentes e sem nenhum escrúpulo para roubar e matar!

Prefiro o militarismo do que a falsa liberdade de ir e vir ou perder a vida para um bandido no meio do dia!

Curtir - Responder - 24 sem

Figura 3 Comentário de internauta, página Jornal Meia Hora, 17 de fevereiro de 2018

Patricia Kovacs Se saúde, educação e afins modificassem o caráter de alguém. Nossos políticos são prova viva e cabal de que mesmo com tudo de bom que o mundo oferece, ainda assim são bandidos.

Há cinquenta anos, $75 \%$ da população brasileira era analfabeta. Não havia hospitais. A pobreza era norma geral. E quantos bandidos haviam naquela época?

Chega dessa falácia esquerdista de que pobreza gera criminalidade. O mau caráter do indivíduo que faz dele o bandido.

Curtir - Responder - 27 sem 
Figura 4 Comentário de internauta, página da revista VEJA, 20 de fevereiro de 2018

Marcello Araujo Isso o seria o correto antes de fazerem a intervenção no Rio exército deveria ter feito em Brasilia. Por que é lá que está origem da corrupção que desencadeia vários outros problemas no país inteiro. Hoje é o rio de Janeiro amanhã pode ser no Ceará Roraima Pernambuco. Com certeza exercito não vai dá conta não tem efetivo pra isso intervenção e uma medida que não resolve problema de forma definitiva. Aliás país inteiro está violento números mostram isso não é por que houve intervenção no Rio de Janeiro que os outros estados estão numa situação melhor. Melhor intervenção que poderia ocorrer no Brasil seria povo na ruas demonstrando seus descontentamento de forma pacifica. Mais os Brasileiro prefere ir ruas mostrar o quanto é alienado mesmo diante dos números absurdo da violência. Milhares de pessoas senão pais inteiro preferem ainda pular carnaval sem ser importar se vão morrer vitima da violência que já se tornou banal e só cresce no pais.

Curtir - Responder - 25 sem

Figura 5 Comentário de internauta, página Socialista de iPhone, 18 de fevereiro de 2018

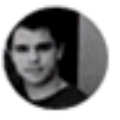
Luis Fernando Nussbaum Deschamps Acho que os militares deveriam ser chamados para todos os Estados brasileiros e solucionar o problema da segurança. Mas infelizmente não vai resolver. O problema moral do Brasil é sério.

Curtir - Responder - 26 sem - Editado

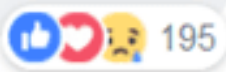

Figura 6 Comentário de internauta, página Profissão Militar, 24 de fevereiro de 2018

Pablo Brum Temos que acabar com esse valores trocado em nossa sociedade, bandido, assassino, globo e corruptos isso não presta, só cadeia. Valores tem que ser na familia, profissão, honestidade, respeito e moral. Não podemos sermos considerados rales pelo mundo.

\section{Curtir - Responder - 25 sem}


Uma segunda suspeita sobre a Intervenção Federal foi a de que se tratava, na verdade, de um jogo por parte da "Organização", momentaneamente capitaneada pelo presidente Temer, eleito em coligação com um partido de esquerda, para diminuir a viabilidade de candidaturas conservadores nas eleições presidenciais que se aproximavam, citando normalmente o candidato Jair Bolsonaro como alvo da manobra.

Figura 7 Comentário de internauta, página Socialista de iPhone, 18 de fevereiro de 2018

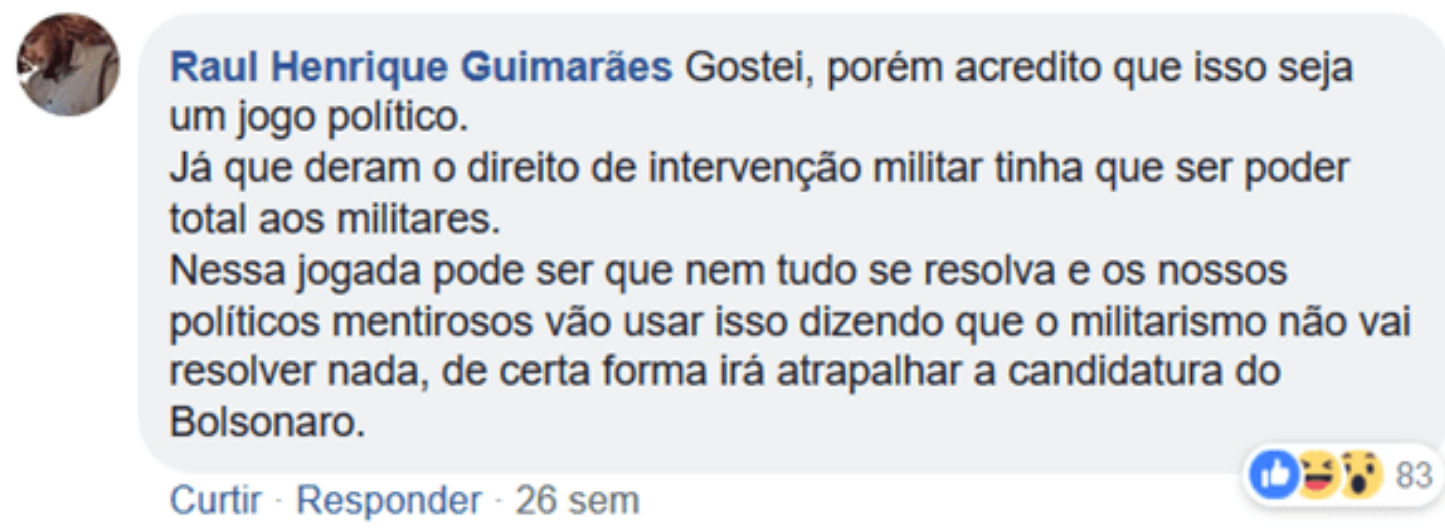

A partir de então, podemos encontrar na reflexão conservadora sobre a intervenção federal o primeiro indício da presença da mesma mitologia política da "conspiração", no símbolo dos bandidos. Estes seres das sombras "encarnam o Estrangeiro no sentido pleno do termo" (GIRARDET, 1987, p. 43), e não se limitam a submeter-se apenas a suas próprias leis. "A ameaça que essas figuras inspiram é aquela mesma que jamais deixou de assombrar os pesadelos das cidades pacíficas e ordeiras: a do vagabundo, que com sua simples presença rondando os bairros já ameaça a felicidade dos lares." (FONSECA, 2014a) 
Figura 8 Comentário de internauta, página Marielle Franco, 23 de fevereiro de 2018

Bruno Lima Bom mesmo é o bandido roubando carga e distribuindo na favela, mas botando toque rmde recolher, pegando as meninas bonitas da favelas e as aliciando e destruindo familias com drogas . Bom e como tá a população perdendo a vida seus bens sem direto a defesa . Quem postou isso que vá pro inferno...

Curtir - Responder - 25 sem

Figura 9 comentário de internauta, página Marcelo Freixo, 27 de fevereiro de 2018

Vinicius Baltazar Alonso Freixo explique porque os moradores da favela Vila Kennedy estão aplaudindo os militares se o senhor disse que os pobres seriam contra.... https://noticias.uol.com.br I.../moradores-da-vila-kennedy...

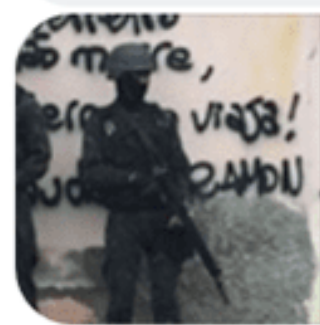

NOTICIAS.UOL.COM.BR

'Matam um todo dia': moradores de favela com ação militar denunciam...

Curtir - Responder - 25 sem 
Figura 10 Comentário de internauta, página Dilma Rousseff, 19 de fevereiro de 2018

Marcelo Tinoco "A presidente Dilma Rousseff assinou, nesta sexta-feira, o decreto de garantia da lei e da ordem (GLO), autorizando o deslocamento de tropas das Forças Armadas para atuar no combate ao crime organizado no Rio." (O GLOBO 2014).

https://m.oglobo.globo.com/.../dilma-assina-decreto-de...

Ue, Dilma Russefi isso não feriu a constituição naquela época? De acordo com o decreto, o exército e toda força nacional teriam autoridade para revistar, prender e até prestar suporte a polícia do Rio em operações nas comunidades. Tudo isso, claro para recebermos os turistas para Copa MAIS CARA do Mundo.

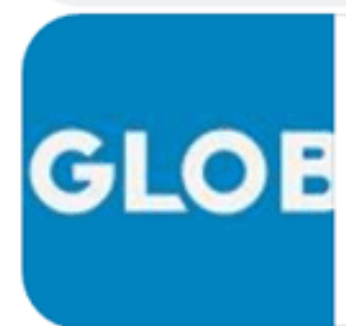

OGLOBO.GLOBO.COM

Dilma assina decreto de Garantia da Lei e da Ordem para o Rio

Curtir - Responder - 25 sem

Figura 11 Comentário de internauta, página Dilma Rousseff, 19 de fevereiro de 2018

Nascim Roberto Realmente Intervenção militar não resolve! O que resolve é fazer como LULA apoiar Sergio Cabral pra roubar o estado e deixar a população morrendo a tiros pela bandidagem e por falta de atendimentos nos hospitais, e equanto o povo morre 0 governador apoiado por lula e pelo PT vai pra Paris na farra dos Guardanapos comprar anel e guase 1 milhão pra esposa com dinheiro de proprina, isso ai não gera preocupação do PT não! !

Curtir - Responder - 26 sem 
Figura 12 Comentário de internauta, página Romário Faria, 16 de fevereiro de 2018

Flávia Cristina Concordo. Mas fica a pergunta no ar: será que esses que andam pelas comunidades, com fuzis nas maos, principalmente os menores de idade, querem estudar ou trabalhar com carteira assinada, ganhando um salário minimo? Está na hora é de mudar o codigo penal brasileiro, e tratar bandido como deve ser tratado, pena de morte! Educação realmente é algo que o governo deveria investir... mas tem mt bandido que não quer mudar. Então chega de passar a mão na cabeça desses algozes

Curtir - Responder - 27 sem - Editado

Os bandidos seriam uma espécie de "linha de frente" da "Organização", cujo objetivo final é o "açambarcamento da riqueza pública", por trás da qual estariam os políticos de esquerda - o que inclui praticamente toda a classe político exceto uns poucos ligados a Jair Bolsonaro. O resultado desse avanço da esquerda sobre as instituições políticas e culturais teria, entretanto, levado a uma situação na qual a opinião pública - ou mais corretamente, a opinião publicada - nacional estaria completamente descolada das crenças e valores da maioria da população. "Os nossos formadores de opinião têm baixíssima representatividade social, e a opinião pública hodierna é a opinião de uma pequena elite cultural detentora do monopólio sobre os meios de expressão e a circulação de ideias." (GORDON, 2018, p. 65) Retoma-se aqui o tema da "sujeição total das inteligências" (GIRARDET, 1987, p. 39) através dos meios de comunicação, que seria favorável aos bandidos, contrariando os interesses da população.

Figura 13 Comentário de internauta, página RJTV Bom Dia Rio G1 Rio, 22 de fevereiro de 2018

Fabian Rocha Cadê os direitos humanos para a senhora torturadas pelos traficantes da favela Kelson ? Vamos lá cadê o MP cade a $\mathrm{OAB}$ cadê os defensores de bandido que não querem inteversao militar não são a mãe de vcs né seus crétinos

Curtir - Responder - 25 sem 
Figura 14 Comentários de internautas, página revista VEJA, 20 de fevereiro de 2018

Joel Barroso Por favor alguém me ajude a entender de que lado afinal das contas essa tal de "OAB" está?!...porque francamente ela só dar bola fora, parece que defende mais os bandidos do que o próprio cidadão, sempre indo contra a maré!!...

Curtir - Responder - 26 sem

Figura 15 Comentário de internauta, página Socialista de iPhone, 23 de fevereiro de 2018

Symonsen Acorroni Quem apóia a intervenção federal: cidadão comum, que pega metrô e sai todo dia pra trabalhar.

Quem não apóia: o cidadão que tem iPhone e discute "justiça social" com seus amigos lacradores.

Tirem suas conclusões

Curtir - Responder - 25 sem - Editado

Figura 16 Comentários de internautas, página revista VEJA, 20 de fevereiro de 2018

Felipe Lima A criação da Força Nacional de segurança não é prevista pela CF e vcs não contestaram. O ministério da segurança pública e seu funcionamento não é previsto pela CF e vcs também não contestaram. Mas, foram contra a prisão após a segunda instância e agora são contra isso. Para que já tá feio a defesa que vcs fazem dos bandidos.

Curtir · Responder $\cdot 26 \mathrm{sem} \cdot$ Editado

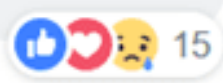


Figura 17 Comentário de internauta, página Portal G1, 20 de fevereiro de 2018

\section{Max Monteiro Atenção.}

Eu sou especialista em especialistas.

Neste caso do Rio estes especialistas não podem ser especialistas, pois é único.

Logo, não há ainda especialista sobre ações deste perfil.

Desqualifico portanto estes especialistas, por não terem experiência.

Bom dia .

\section{Curtir - Responder - 26 sem}

\section{O EXÉRCITO COMO SALVADOR DA PÁTRIA}

Ao final, a luta da nação contra uma conspiração de bandidos e letrados que tentam destruí-la depende principalmente da articulação dos militares, seus guardiões. "O postulado é simples: o único meio de combater o Mal é voltar contra ele as próprias armas de que se serve." (GIRARDET, 1987, p. 59) As Forças Armadas reuniriam, além dos soldados, o poder de fogo e a disciplina e capacidade de organização necessárias para enfrentar as armas que os homens do complô aprenderam a manejar: "a da corrupção, do aviltamento dos costumes, da desagregação sistemática das tradições sociais e dos valores morais." (idem, p. 40).

Figura 18 Comentário de internauta, página Socialista de iPhone, 23 de fevereiro de 2018

Cristoffer Santoro Regime do tráfico lembra muito regime comunista (por isso comunista e socialista apoia tanto). Aquela de controlar tudo e todos pelo que poder absoluto na base do medo.

Curtir - Responder - 25 sem 
Figura 19 Comentário de internauta, página Quebrando o Tabu, 24 de fevereiro de 2018

(3) Rafael Borges Borjão Favela nao paga imposto, não contribui pra merda nenhuma, só aumenta a vagabundagem de quem nao quer pagar um terreno, e quer só viver de gatos, depois querem vida boa, hospital bom, escola boa, a gente que ja paga imposto e vive de trabalho ja é uma merda, os caras que fica perambulando em becos o dia inteiro quer ter vida de rei, vai se ferrar, ja falei se cada mimizento aqui que tem dó, chamasse o povo de lá pra morar em suas casas, isso vcs nao querem tbm, se a comunidade esta daquele jeito, pq eles contribuiram pra ser assim, então agora segura o rojão.

Curtir - Responder - 26 sem

Figura 20 Comentário de internauta, página Gregório Duvivier, 20 de fevereiro de 2018

Daniel Silveira Respondendo a sua última
pergunta, se sabemos o que aconteceu
quando os militares tiveram tanto poder no
Brasil. Sim, sabemos! Mas antes esclareço
que não perderam poder, apenas atenderam
ao clamor social de entregar aos civis por
intermédio doutrinador da rede esgoto de
televisão. O poder ainda é nosso e sempre
será.
Já respondendo a pergunta... Aconteceu que
comunistas maconheiros foram duramente
perseguidos e jogados para fora da sociedade
de bem. Exilados, esculachados... Melhor que
deixar que a ideologia nascida na escola de
Frankfurt tomasse de vez nosso pais... Enfim,
viciados tem medo de militares
Curtir - Responder - 24 sem


Figura 21 Comentário de internauta, página Senado Federal, 20 de fevereiro de 2018

Flavia Albino TEMER JAMAIS SERA ELEITO! Desistam! Isto nao vai acontecer! Os politicos têm de comecar a receber processos a cada morte q ocorre no país. Se nao forem responsabilizados, tudo fica assim. C vc assumiu compromisso de cuidar da administraçaõ publica, VC VAI SER RESPONSABILIZADO PELO Q ACONTECER NO PAIS.

\section{Curtir - Responder - 26 sem - Editado}

Figura 22 Comentário de internauta, página Olavo de Carvalho, 20 de fevereiro de 2018

\section{Marcos Almeida}

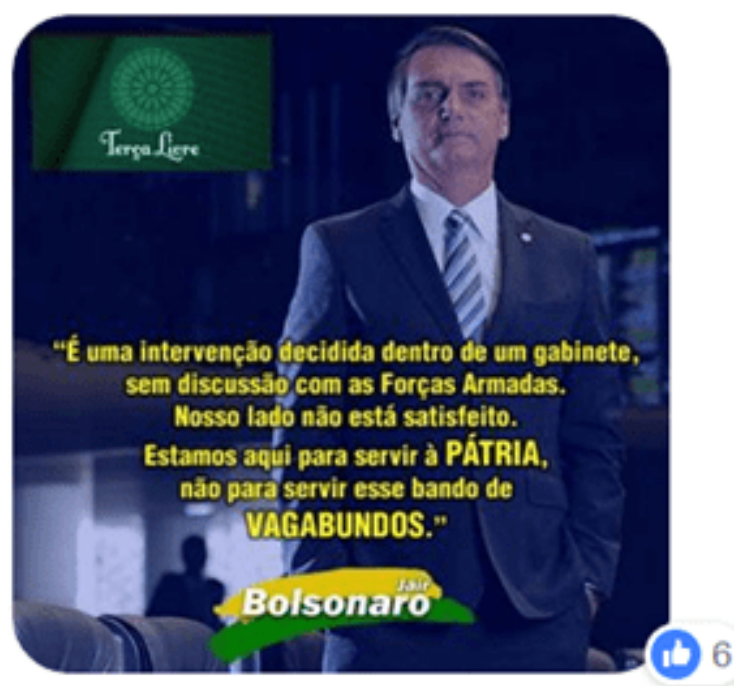

26 sem

\section{OS MEIOS DE COMUNICAÇÃO DE MASSA}

As Organizações Globo são, também, apontadas como a principal ferramenta dos conspiradores no ataque à Intervenção Federal e às Forças Armadas. Nesse caso, a Globo News, um canal a cabo, teria sido identificada como tendo um perfil ainda mais à esquerda do que o da Rede Globo de Televisão. 
Figura 23 Comentário de internautas, página Joice Hasselmann, 26 de fevereiro de 2018

Junior Tinajero Hoje pela manhã na rádio $\mathrm{CBN}$ o desespero do $\mathrm{Sr}$ Kennedy Alencar dizendo que é um absurdo que é um retrocesso um general ser o ministro da defesa!! Ele em nem um momento estava preocupado com nosso país ou se o general e competente para a função de ministro, sua única preocupação era que ele é general!! A esquerda não para de passar vergonha!!

\section{Curtir - Responder $\cdot 48$ sem}

Figura 24 Publicação da página Alexandre Borges, 19 de fevereiro de 2018

19 de fevereiro de 2018 .

Gente, a "especialista" da GloboNews, como todos os outros 100.000 anteriores, é do PSOL. Quem poderia imaginar?

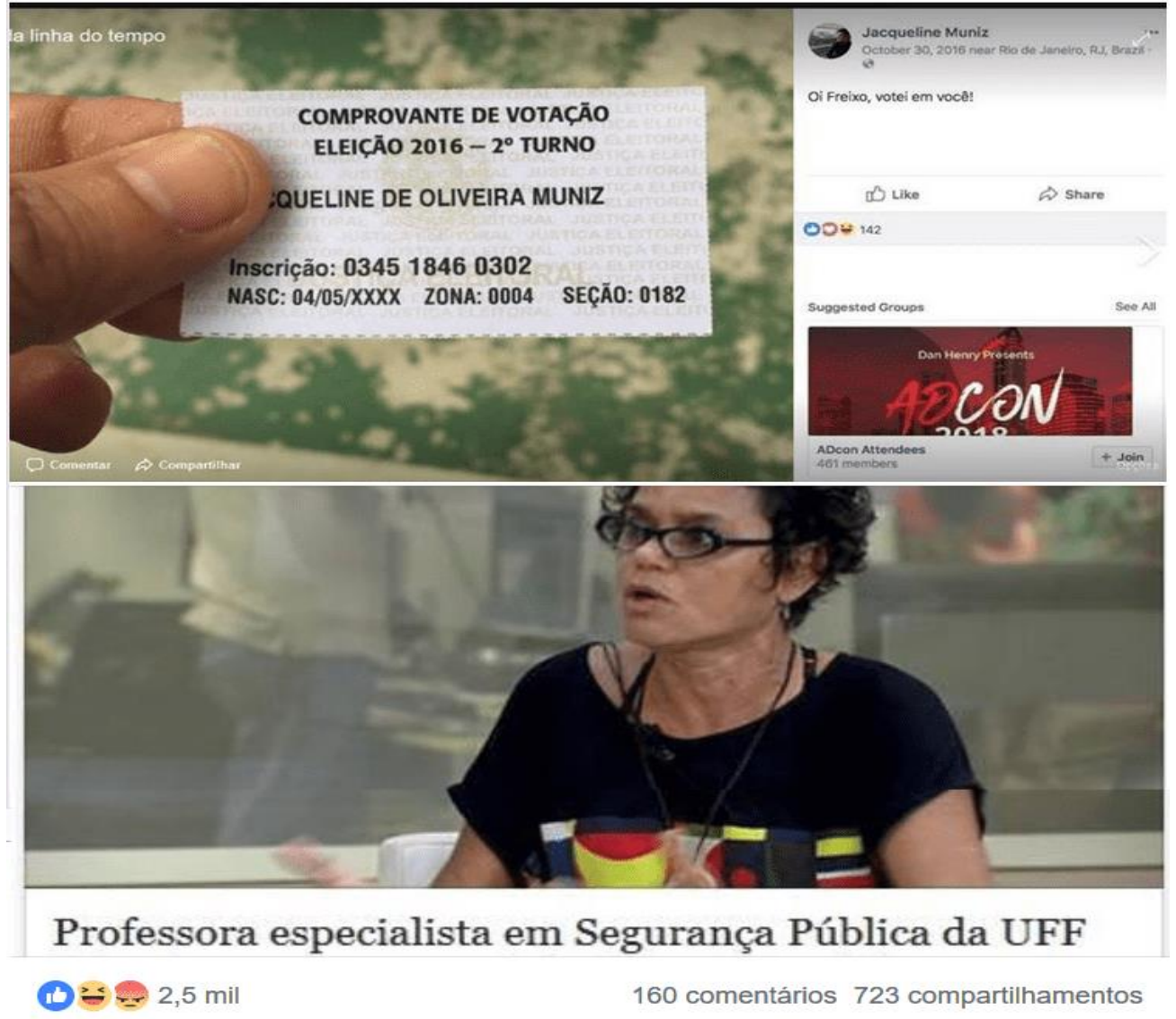

Disponível em: https://www.nucleodoconhecimento.com.br/comunicacao/intervencao 
Figura 25 Comentário de internauta, página revista Época, 17 de fevereiro de 2018

Pc Gastao O importante é a tentativa, o que esse canal afirma, ele não garante que vai acontecer. O que tá havendo, é apenas manipulação dessa mídia sensacionalista.

\section{Curtir - Responder - 27 sem}

Figura 26 Comentários de internautas, página Socialista de iPhone, 23 de fevereiro de 2018

Wagner Percegoni Lembrei da célebre frase do brilhante carnavalesco Joãozinho Trinta: "Quem gosta de miséria é intelectual, pobre gosta de luxo!". Parafraseando para os dias de hoje: "Quem gosta de bandido é artista da Globo, pobre gosta é do Exército na rua!"...

\section{Curtir - Responder - 25 sem}

Rogerio Lopes Reportagem mentirosa!

Fake dos fakes!

A população está clamando pela proteção da Globo News e do PSOL.

\section{Curtir - Responder - 25 sem - Editado}

Figura 27 Comentário de internauta, página Quebrando o Tabu, 27 de fevereiro de 2018

Rodrigo Cordeiro Querendo o Quebrando o Tabu ou não, as forças armadas fazem parte das instituições q compõe a nossa nação, e devem ser integradas as outras para garantir a nossa democracia. Associar Forças Armadas e Ditadura automaticamente é um erro, o passado deve ser uma lição e não uma mácula. A eficácia ou não da intervenção no estado do Rio de Janeiro é algo a se questionar, mas questionar a legitimidade dela e ignorar seu papel na sociedade é dar um tiro no próprio pé.

Curtir - Responder $\cdot 25$ sem 
Para a "Organização", um dos objetivos principais é quebrar a capacidade de resistência da população em geral. Diante ela, apenas a "massa aviltada, dividida e desvairada, desapossada tanto de seus bens como de sua dignidade". É dessa forma que é entendido o apoio a políticas públicas de ataque aos problemas sociais do país, os quais parecem uma forma de se esquivar do real combate aos criminosos. Resta uma forte tendência a satirizar essas propostas como inócuas, quando não absurdas, de maneira a quebrar o possível "feitiço" dos meios de comunicação de massa.

Figura 28 Comentário de internauta, página Spotniks, 16 de fevereiro de 2018

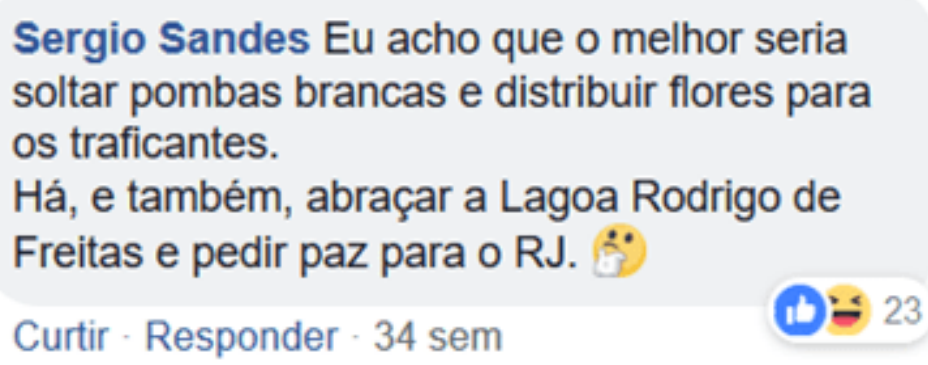

Figura 29 Comentário de internauta, página Jornal Meia Hora, 17 de fevereiro de 2018

Gabriel Costa da Silva Toda vez que se propõe uma solução emergencial como essa, tem sempre uma galerinha pra reclamar, pra dizer que devemos discutir o tema, eleger políticos honestos, dar as mãos pra cantar imagine na praia de Copacabana e soltar umas pombas brancas. Bom mesmo é protestar com plumas, paetês e fantasias ridiculas como fizeram no carnaval, não é mesmo? O Rio está um caos e essa gente no conforto dos seus lares, porque moram bem, querendo falar de politica, de militância, de golpe, de mortadela, de coxinha. Acordem!

\section{Curtir - Responder - 27 sem}

Aline Souza Achei equivocada a intervenção Federal no Rio... o correto seria entrar na favela com um trio elétrico, Caetano, Chico Buarque e uns globais cantando "Imagine" do John Lennon. Já consigo ver os bandidos entregando as armas e cantando junto... não tem como dar errado!

Curtir - Responder - 27 sem - Editado 
Figura 30 Comentário de internauta, página Dilma Rousseff, 19 de fevereiro de 2018

Humberto Nemer Tem razão Dilma, deveriamos soltar umas Pombas Brancas nos morros, ou quem sabe chamar o pessoal do Afro Reggae para fazer um Sarau com os traficantes, outra ideia seria um show do Caetano Veloso somente para os líderes do CV. Tem razão, DILMANTA!

Curtir - Responder - 26 sem

Figura 31 Comentário de internauta, página revista VEJA, 20 de fevereiro de 2018

Eric Vieira Vanderley É que se os militares darem fim nos vagabundos eles vão perder clientes, por isso estão preocupados. Vê se um deles esta nas ruas lutando com flores e abraços pra diminuir a violência

Curtir $\cdot$ Responder $\cdot 26$ sem

Figura 32 Comentário de internauta, página Pragmatismo Político, 24 de fevereiro de 2018

Rose Furlan Preferem a violação feita pelos traficantes, que impõe espaço e zonas de permissão para acesso de moradores ? É preciso ceder para conquistar paz, os militares não podem levar flores para o tráfico, tem que conhecer os moradores para saber quem é quem e se eles não colaboram não podem reclamar depois.

Curtir - Responder - 26 sem

(1) : $: 35$

Figura 33 Comentário de internauta, página Marcelo Freixo, 27 de fevereiro de 2018

Renata Alves Tem que ser assim e quem não deve, não teme! Vc tem ideias melhores sem ser iluminação, flores e drogas? Num ferra... Bota a cara na favela, seu hipócrita!

Curtir - Responder - 24 sem - Editado

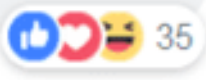

RC: 39118

Disponível em: https://www.nucleodoconhecimento.com.br/comunicacao/intervencao 


\section{PURIFICAÇÃO PELO FOGO}

$\mathrm{Na}$ condição de espíritos do mal, os bandidos só podem perecer pelo fogo, da mesma maneira que os processos de feitiçaria terminavam com condenação à morte pelo fogo. "A simbólica do fogo, do fogo purificador e redentor que apaga as máculas, que dissipa as angústias da noite e faz recuar os poderes das trevas, acaba de dar toda sua coerência à constelação mítica da Conspiração." (GIRARDET, 1987, p. 48-9) Com poder de fogo supostamente superior ao da Polícia Militar - a Inquisição habitual dos Estados - as Forças Armadas passam a representar, além do papel de conservadores da nação brasileira, o de seus salvadores. "Os Filhos da Luz contra os poderes das Trevas, (...) o eterno combate no qual o mundo é a aposta prossegue à nossa volta." (idem, p. 49)

Figura 34 Comentários de internautas, página O Antagonista, 27 de fevereiro de 2018

Andre Cardozo Sério? Que lamentável. Podem ir embora então.

E eu achando que era um trabalho de recomposição da paz e da cidadania expulsando, prendendo ou matando os vagabundos.

Que dinheiro e tempo desperdiçados General.

\section{Curtir - Responder - 25 sem}

João Magalhães "Gestão" de como eliminar ALVOS armados definitivamente !!! Limpeza geral ...

Curtir - Responder - 25 sem 
Figura 35 Comentário de internauta, página Romário Faria, 16 de fevereiro de 2018

Eduardo Nascimento Primeiro passo é afastar esses direitos dos manos e mandar eles pra PQP,

Depois nas principais favelas do RJ toque de recolher depois das 22 horas.

O tráfico vai viver de quê? Vamos sufocar a entrada e saída. Não entra drogas nem armas.

E aqueles que encararem o exército vai pra vala sem misericórdia.

Estamos numa guerra.

Curtir - Responder - 27 sem

Figura 36 Comentário de internauta, página Polícia no Sangue, 20 de fevereiro de 2018

Edval Santos Eles não tem que querer disgraça de nada isso ai já é obrigação do governo fazer rapaz! Senta o açoooooiooo disgraça ninguém aguenta mais tanto ladrão !

Curtir - Responder - 25 sem

Figura 37 Comentário de internauta, página RJTV Bom Dia Rio G1 Rio, 22 de fevereiro de 2018

Adilson Salgadinho Deu uma bola dentro o \#Interventor. Se coloca um Coronel da cúpula, continuaria tudo como antes. Agora, é só botar um oficial superior no comando de cada batalhão e partir pra \#Guerra. Nos alvos em frente. \#Fogo à vontade! * $\therefore$ क

Curtir - Responder - 25 sem 
Figura 38 Comentário de internauta, página O Globo, 23 de fevereiro de 2018

Raimundo Severino da Silva Pelos bigides já vi que os caras são homens de peito e coragem. Todos os lideres militares que usavam bigode eram ousados e intolerantes com os subversivos e com a marginalidade.

Curtir - Responder - 26 sem

Figura 39 Comentário de internauta, página Profissão Militar, 24 de fevereiro de 2018

Robinho Gomes Excelente texto.

Exército é feito para atirar primeiro e quem não quiser morrer que se renda.

Nós somos o caos. A guerra.

excelente

Curtir - Responder - 26 sem

Figura 40 Comentário de internauta, página Jacarepaguá Notícias RJ, 26 de fevereiro de 2018

Elitusalem Freitas Leandro Sant'ana não peço emprego não! Já sou concursado e não temos mais nada a provar a ninguém!

A guerra está aí, há dez anos o bosta do Beltrame colocou de lado os infantes, são mais de duzentas prisões em flagrante, 18 autos de resistência, se nos quiserem sabem onde achar!

Força e Honra!!!

Curtir - Responder - 25 sem

Por fim, a presença dos militares traz esperança a esta parte do público. Ao contrário do bandido, que é visto como o "Estrangeiro", os militares representam sua antítese, isto é, aqueles que melhor encarnam os valores da nacionalidade e, por isso, são os 
únicos capazes de oferecer combate à dominação das organizações criminosas e seus representantes na mídia, na política e no aparelho judiciário.

Figura 41 Comentário de internauta, página Jornal Hoje, 16 de fevereiro de 2018

\section{Denise Mitre É uma questão de tempo para todo o país estar pedindo que os homens e mulheres de principio patriótico venham também para ajudar em todas as áreas, o povo honesto vê as Forças Armadas é a solução de integridade que falta aos politicos.}

\section{Curtir - Responder - 34 sem}

\section{CONSIDERAÇÕES FINAIS}

A observação do comportamento do público nas mídias sociais permitiu levantar com mais clareza o ambiente de polarização ideológica estabelecido no país em consequência dos eventos de junho de 2013 e sua influência decisiva na imagem da Intervenção Federal diante desse mesmo público. Embora ele esteja também presente em produtos da mídia tradicional, até como resposta a uma demanda do próprio público dos meios, nas mídias sociais a fabricação da segunda realidade aparece em estado puro, sem a preocupação com os padrões de qualidade estabelecidos pelo mercado de notícias. Observa-se que essa fabulação, no fundo, nada tem de original. Ela repete motivos e estereótipos comuns às mitologias políticas estudadas por Girardet (1987), e presentes na romantização de acontecimentos no Ocidente em todo o período pós-Revolução Francesa.

Em síntese, o Exército Brasileiro aparece nesta narrativa como uma espécie de "Salvador", no combate à "Organização" que tentava destruir o Brasil com o auxílio dos meios de comunicação de massa. Deve-se acrescentar, também, que o emprego de violência é o meio preferido para a destruição da "Organização".

Não é uma grande inovação deste trabalho argumentar que a alienação individual do homem é o problema central da modernidade. Girardet (1987, p. 181) explica que ela é, afinal, a causa principal da efervescência mitológica que acompanha as grandes 
transformações políticas a partir do fim do século XVIII. "O drama, sem dúvida, é o da alienação. Mas é subjetivamente - enquanto sentimento pessoal e intimamente vivido - bem mais que pelas condições consideradas como objetivas de seu desenvolvimento, que deve ser definido o estado de alienação."

\section{REFERENCIAS}

ARAÚJO, E. H. F. Trump e o Ocidente. Cadernos de Política Exterior, Brasília, 3, n. 6, dezembro 2017. 323-358.

BESANÇON, A. A imagem proibida: uma história intelectual da iconoclastia. Tradução de Carlos Sussekind. Rio de Janeiro: Bertrand Brasil, 1997.

BURKE, E. Reflexões sobre a Revolução na França. Tradução de José Miguel Nanni Soares. São Paulo: EDIPRO, 2014.

CARVALHO, O. D. O Jardim das Aflições: de Epicuro à ressurreição de César: ensaio sobre o materialismo e a religião civil. 2. ed. São Paulo: É Realizações, 2000.

CARVALHO, O. D. O mínimo que você precisa saber para não ser um idiota. 8. ed. Rio de Janeiro: Record, 2014.

DA MATTA, R. O que faz o brasil, Brasil? Rio de Janeiro: Rocco, 1986.

DUARTE, M. Y. M. Estudo de caso. In: DUARTE, J.; BARROS, A. Métodos e técnicas de pesquisa em comunicação. 2. ed. São Paulo: Atlas, 2017. p. 215-235.

FONSECA, A. A. D. O mito das teorias da conspiração (Introdução aos estudos da mitologia política - parte 4 de 6). Youtube, 30 Dezembro 2014a. Disponivel em: $<$ https://www.youtube.com/watch?v=Bh4ChRjlJy8\&list=PL0k4Oibql6p6fbonBdOuLjGZiM1MEFn8\&index=4>. Acesso em: 8 Agosto 2017.

GARSHAGEN, B. Pare de acreditar no governo: por que os brasileiros não confiam nos políticos e amam o Estado. 5. ed. Rio de Janeiro: Record, 2015. 
GIRARDET, R. Mitos e mitologias políticas. [S.I.]: [s.n.], 1987.

GORDON, F. A corrupção da inteligência: intelectuais e poder no Brasil. 7. ed. Rio de Janeiro: Record, 2018.

KIRK, R. A política da prudência. Tradução de Gustavo e Brito, Márcia Xavier de Santos. São Paulo: É Realizações, 2013.

MARTINO, L. C. Interdisciplinaridade e objeto de estudo da comunicação. In: HOHLFELDT, A.; MARTINO, L. C.; FRANÇA, V. V. Teorias da comunicação: conceitos, escolas e tendências. 15. ed. Petrópolis: Vozes, 2015. p. 27-38.

MILLS, C. W. A elite do poder. Tradução de Waltensir Dutra. 4. ed. Rio de Janeiro: Zahar Editores, 1981.

RODRíGUEZ, R. V. Patrimonialismo e a realidade latino-americana. 2. ed. Rio de Janeiro: Biblioteca do Exército, 2017.

SCRUTON, R. O que é conservadorismo. Tradução de Guilherme Ferreira Araújo. São Paulo: É Realizações, 2015b.

VOEGELIN, E. Hitler and the Germans. Columbia: University of Missouri Press, 1999.

WEBER, M. A ética protestante e o "espírito" do capitalismo. Tradução de José Marcos Mariani de Macedo. São Paulo: Companhia das Letras, 2004.

ZIZEK, S. Acontecimento: uma viagem filosófica através de um conceito. Tradução de Carlos Alberto Medeiros. Rio de Janeiro: Zahar, 2017.

\section{APÊNDICE - REFERÊNCIAS DE NOTA DE RODAPÉ}

2. Na França, as comemorações da Revolução Francesa acontecem no aniversário da tomada popular da prisão da Bastilha, em14 de julho. Também é comemorada com um desfile de tropas. 
3. Folha de São Paulo: "Militares falharam em não combater comunismo, diz Olavo de

Carvalho em $\quad 1^{\text {a }} \quad$ Cúpula $\quad$ Conservadora".

https://www1.folha.uol.com.br/poder/2018/12/militares-falharam-em-combater-

comunismo-diz-olavo-de-carvalho-em-1a-cupula-conservadora.shtml

Enviado: Agosto, 2019.

Aprovado: Outubro, 2019. 